structure on its research plans, ensured that Spain established itself in important competitive areas such as biotechnology, engineering and microelectronics.

The increase in Spain's scientific stature has been largely led by the CSIC and its 96 research institutes, 42 of which are in Madrid. But CSIC is now also suffering a budget squeeze, with only a six per cent increase, close to the inflation rate, for 1993. Between 1983 and 1990, the average budget growth was around 17 per cent. There are no strong indications that the universities or industry will pick up the slack. According to Francisco Mora, a university professor in Madrid, "the scientific infrastructure in the universities is far behind that of CSIC". And Fereres admits that despite his government's encouragement, "Spain traditionally imports technology and industry lacks the commitment to do research." In 1988, the government introduced a scheme to pay for one-year contracts for young scientists to work in an industrial environment, and many research-linked tax incentives are now available. But the hope that this would stimulate the fledgling research and development culture in Spanish companies has not yet been fulfilled.

Another source of new money for Spanish science is the EC, and about 1,350 Spanish groups now participate in 955 different EC projects. But they are leaders in only 4 per cent of those projects, which is a measure of how far Spain is away from what Luis Oro, secretary general of the national plan, calls "the ultimate goal of reducing the gap separating Spain from the most advanced industrial countries." Oscar G. Segurado

\section{Physics centre threatened}

Washington. Fusion research at the Princeton Plasma Physics Laboratory (PPPL), one of the principal US fusion research centres, would be shut down for as long as nine years under a recent plan submitted to the US Department of Energy (DOE). The Fusion Energy Advisory Committee, which was asked by DOE to rank US fusion projects, recommended closure of the Princeton Beta Experiment-Modification (PBX-M) in 1994, on the grounds that the $\$ 10$ million annual cost would be better spent on the International Thermonuclear Experimental Reactor, to which the United States is a subscriber, and on PPPL's new project, the Tokamak Physics Experiment. The TFTR (Tokamak Fusion Test Reactor) at Princeton is scheduled to be shut down in 1994, and the Tokamak Physics Experiment is not due for completion until 2003. Closure of PBX-M will displace 25 scientists, unless the budget for fusion energy research rises by 5 per cent for the next several years, which seems unlikely in the light of this year's increase of only 0.8 per cent. Traci Watson

\title{
Proposal opens debate over US data on animals
}

Washington. A proposal that the US government should collect more data on research animals has renewed debate about the flaws in the existing system. Although many researchers believe that additional information is unnecessary and could be used by activists campaigning to eliminate animals from the laboratory, most agree that changes are needed in what is now collected.

At present, institutions must submit an annual report to the US Department of Agriculture (USDA) on animals used for

\section{Animals in the laboratory}

There were 1.8 million animals used in US experiments in 1991, excluding rats, mice and birds.

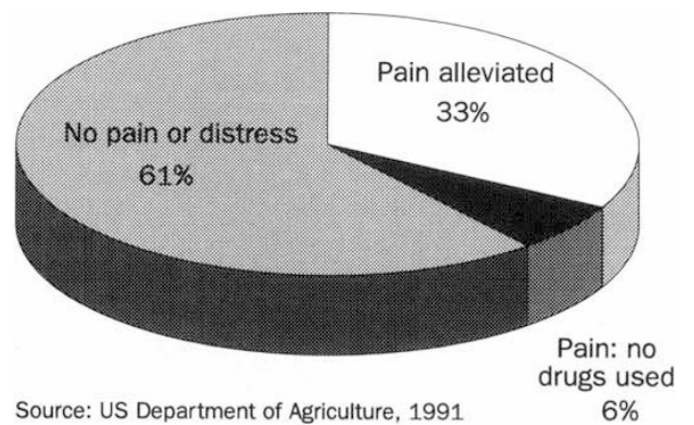

Proposed categories of pain and suffering

Category 1: Procedures involving the use of microorganisms, plants, invertebrates, vertebrate embryos, in vitro cultures, or no living organisms at all. Category Il: Procedures using vertebrates species that should produce little or no pain or discomfort.

Category III: Procedures that should produce minor or short-term pain or distress in vertebrate animals.

Category IV: Procedures involving significant (moderate to severe) but unavoidable pain or distress to vertebrate animals.

Category V: Procedures involving severe pain near, at, or above the pain tolerance or unanesthetized, conscious animals.

research, testing or education. Scientists have long complained that the rules for the annual report are vague and unreasonable, especially the requirement that all animals be placed into one of three categories that measure pain and distress: those experiencing no pain, those subjected to painful procedures and treated with alleviating drugs and those that undergo painful procedures without any alleviating drugs.

Reporting varies widely between institutions and among investigators. Even a simple injection may or may not be reported as painful, says Franklin Loew, dean of the school of veterinary medicine at Tufts University in North Grafton, Massachusetts.

Researchers and animal advocates agree that the present statistics are probably misleading. For example, USDA says that only
6 per cent of research animals are subject to painful procedures undrugged; many researchers think the figure is too high, and advocates contend that it is too low.

The Humane Society of the United States has submitted a proposal to USDA for a pain that provides "a better profile of what laboratory animals experience". Their scale has five categories, based on the degree of ure). Pain scales more extensive than USDA's are already used in some European countries and at least a dozen large US research institutions. In 1987, USDA proposed a detailed pain scale for use by the committees that oversee animal care at each institution, but it was withdrawn after researchers complained that it was vague and too subjective. Many are also concerned that such information would be used by animal advocates to turn public sentiment against the scientific community.

It is unlikely that USDA will support the Humane Society's request, but there is room for improvement. Many researchers believe that a thorough explanation of the reporting requirements would yield more accurate information, and they would like to work with the agency on such changes. "USDA has never come to the community asking for help", says one researcher. "Doing so would show that they're serious." Scientists believe they have an ally in Dale Schwindaman, the new director of the USDA department that collects the annual reports. They are encouraged by his agreement to rescind changes in a rule that would have made the statistics less accurate and by his appearance earlier this month at the annual meeting of the American Association of Laboratory Animal Science.

But substantive changes will demand more than just good will. The USDA department that oversees animal research is understaffed and overworked; compiling more information and explaining the current system may be asking too much. Both animal activists and scientists agree that a necessary first step would be a larger USDA budget.

Traci Watson 